\title{
ВЛИЯНИЕ СМИ НА ФИНАНСОВУЮ БЕЗОПАСНОСТЬ ПРЕДПРИЯТИЯ
}

\author{
(C) 2019 Головин Валерий Сергеевич \\ аспирант \\ Российская академия народного хозяйства и государственной службы \\ при Президенте Российской Федерации (РАНХиГС), Россия, Москва \\ E-mail: researchergolovin@mail.ru
}

В статье рассматривается вопрос влияния СМИ по отношению к финансовой безопасности предприятия, рассмотрены риски вероятных утечек информации в контексте экономической безопасности. Использован метод теоретического исследования в аспектах раскрытия информации предприятия СМИ. Приведены способы принятия решений в условиях, когда возникает необходимость к решительным шагам внутри организации, например, заключение сделки с контрагентом с учётом влияния СМИ. Область применения результатов: экономическая безопасность предприятия.

Ключевые слова: Финансовая безопасность, СМИ, влияние, дестабилизация, риски, экономика, информационная среда.

\section{Введение}

СМИ довольно прочно вошли в нашу повседневную жизнь. Довольно малое количество людей подходят к информации из СМИ критично, подвергая критическому анализу информацию, либо не задумываясь о целях распространения той или иной информации. В настоящее мнение существует проблема переизбытка информации, которое грозит чередой проблем, связанных с «клиповым мышлением», большого количества непрочитанной важной литературы с позиции развития моральных качеств, проблем, связанных с грамотным распределением времени как главного человеческого ресурса на просторах информационной среды - это очень важные проблемы социального характера, на которые необходимо сосредотачивать мировой научноисследовательский потенциал.

СМИ играют неотъемлемую роль в жизни общества, затрагивая внушительное количество жизненных аспектов в ключевых сферах деятельности. В отношении экономики СМИ могут являться инструментом для манипуляций и инструментом изменений важных финансовых показателей предприятий любого государства. В научных изданиях довольно редко можно встретить публикации на тему манипуляций в плане финансовых показателей при помощи СМИ, уделяется внимание в основном идее фундаментального анализа, т.е. сбору и последующему анализу информации, которая повлияла на стоимость активов [1]. Моменты, которые бы апеллировали к взаимодействию финансовой безопасности и СМИ крайне редко затрагиваются, или же приводятся совсем неоднозначные трактовки, относящиеся к вопросам информационной безопасности что является некорректной ошибкой.

Финансовая безопасность как термин стал рассматриваться относительно недавно и главным образом акцентирует внимание на государстве (Рис. 1), о предприятиях отводится малое место. Понятие финансовой безопасности предприятия представляет комплексную сохранность таких важных аспектов как:

- коммерческая тайна;

- персональные данные сотрудников;

- интеллектуальная собственность;

- защита предприятия от факторов негативного воздействия окружающей среды, а именно способность активно реагировать на различные неблагоприятные факторы.

Если брать первые три пункта, перечисленные выше, то подразумеваются утечки информации вследствие инсайдерства или же технических уязвимостей в используемом на предприятии оборудовании. Зачастую львиная доля утечек информации происходит по вине инсайдеров на руководящих или рядовых должностях (Рис. 2). Однако, утечки важной информации для предприятия могут возникать также по слабому соблюдению или не соблюдении правил работы с коммерческой тайной, персональными данными сотрудников и интеллектуальной собственностью предприятиях [2]. Угроза СМИ в данном случае заключается в дезинформации 


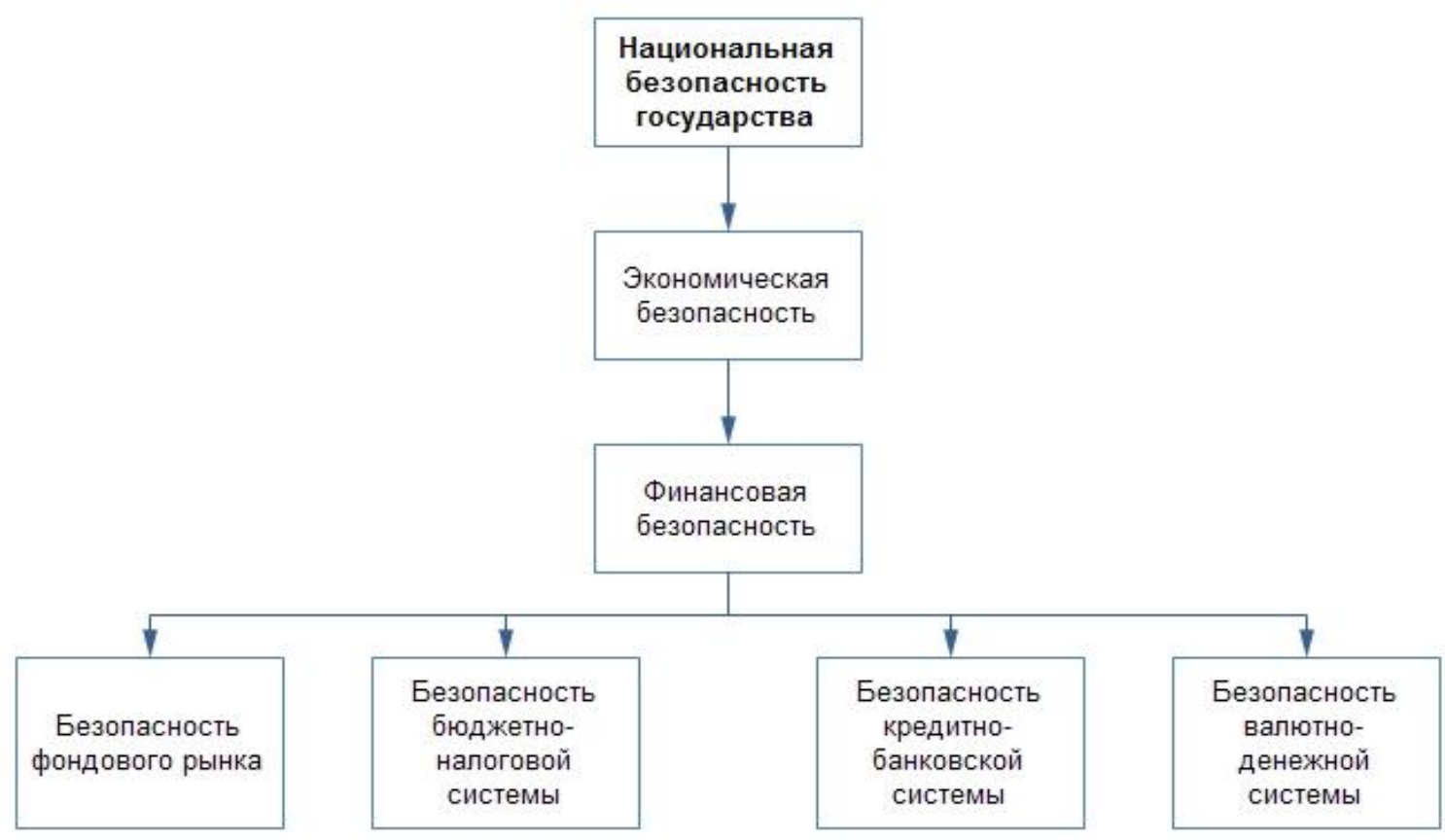

Рисунок 1. Структура финансовой безопасности государства

\section{ВИНОВНИКИ УТЕЧКИ ВНУТРИ ПРЕДПРИЯТИЯ}

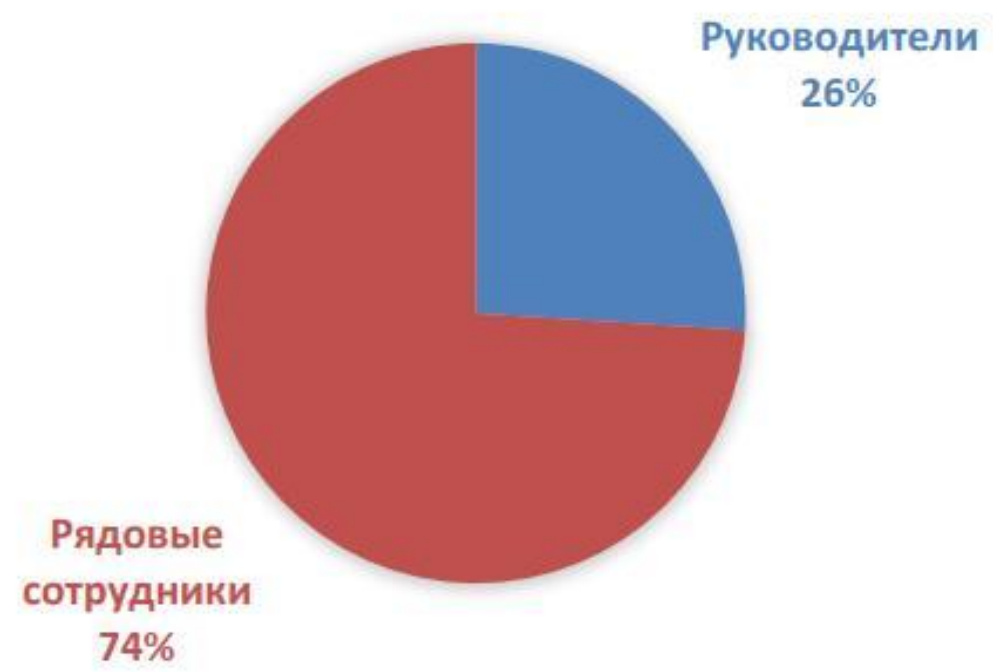

Рисунок 2. Диаграмма виновников утечки информации внутри предприятия 
сотрудников и руководителей предприятия в технических, организационных и финансовых вопросах. Например, реклама обслуживающих инженерных компаний, имеющих низкоквалифицированный персонал что в конечном счёте приведёт к утечке важной для предприятия информации.

\section{Основная часть}

Защита предприятия от факторов негативного воздействия окружающей среды возможна при условии достаточного капитала на банковских счетах, наличию свободных активов, отсутствию «теневых» финансовых схем и др. Угроза СМИ в данном случае может включать навязчивую информацию, пропагандирующую переход на рисковые финансовые инвестиции с быстрой максимизацией конечной прибыли, или же зарубежные банки, которые на практике могут оказаться ненадёжными [3].

Финансовая безопасность предприятия, в отношении ресурсно-функционального метода, представляется как высокоэффективное использование ресурсов предприятия для активной минимизации рисков и последующего обеспечения бесперебойности основного функционала предприятия [4].

На уровень финансовой безопасности предприятия оказывает важное влияние:

- эффективное управление капиталом;

- качественный уровень финансового менеджмента в управлении структурой предприятия;

- оснащение информационно-технологической базой и регулярное обновление информационной базы;

- квалифицированный уровень аудирования;

- выявление и последующая проработка экономических рисков;

- высокий уровень адаптации к быстроменяющейся рыночной конъюнктуре.

Следует отметить что СМИ акцентируя внимание на предприятии могут использовать различные типы раскрытия информации, такие как:

1) Добровольное (информация, раскрываемая предприятием на добровольной основе);

2) Обязательное (информация, раскрываемая по требованию законодательных норм);

3) Незаконное (инсайдерская информация, похищение информации в результате хакерской атаки).
Угроза раскрытия информации о предприятии, которая не планировалась быть раскрыта может вылиться в ряд негативных событий для предприятия вплоть до его полного банкротства, потому СМИ можно считать опасным инструментом подрыва финансовой безопасности и имиджа предприятия. Также, стоит отметить, что информация о предприятии, которую транслируют СМИ может быть неверной и заказанной конкурирующими предприятиями с целью убрать конкурента на рынке продукции, т.о. повысив спрос и увеличив выгоду реализации своей продукции [5].

Теоретически, СМИ должны беспристрастно освещать финансовую информацию о предприятии, однако, в силу заинтересованности акцент положительной/отрицательной оценке субъективного видения сотрудника, освещающего информацию может сильно варьировать. Относительно рынка СМИ оказывают влияние на:

- выбор товаров/услуг потребителями;

- предоставление информации о вакантных рабочих местах на предприятии;

- создание оценки события в нейтральном или же в субъективном видении сотрудника, освещающего информацию.

Все три пункта могут оказать негативное влияние на финансовую безопасность предприятия.

Даже если сознательно информация показалась для большинства незначительной это не значит, что она не будет фигурировать в бессознательных действиях людей. Так, например, прочитав в газете об утечке персональных данных клиентов нашего банка в сеть Интернета, мы неосознанно будем искать более надёжный банк, где подобных инцидентов не происходило [6]. Данная информация могла быть неверно проинтерпретирована СМИ на изначальном этапе анализа полученных данных, могла быть существенно преувеличена или же являться дезинформацией. Стоит обратить внимание на момент тиражированности события СМИ что существенно усиливает негативный эффект направленный на подрыв финансовой безопасности, чем больше СМИ задействовано в освещении события под характерным углом, тем больше вероятность увеличения финансовых потерь рассматриваемого предприятия.

Сенсационная природа СМИ может привести к тому, что люди будут принимать необдуманные, импульсивные решения, основанные на 
ограниченном потоке информации. И, если это не удастся, те, кто распространял информацию, вряд ли будут привлечены к ответственности. Расследование данных инцидентов практически не имеет шансов на успех.

Финансовую безопасность предприятия необходимо регулярно укреплять, повышать качество стратегии обеспечения финансов (движимых и недвижимых активов), расширять линейку мер по предотвращению инцидентов связанных с манипуляцией СМИ на принятие взвешенных решений по финансам предприятия. Мониторинг, анализ и планирование - те необходимые составляющие, которые могут помочь в предотвращении необдуманных решений в финансовом менеджменте [7].

Влияние СМИ на финансовую безопасность может иметь довольно серьёзные последствия, растянутые в интервале большого времени на жизни людей, так или иначе связанных с экономикой предприятия, т.е. чьи-то эксперименты в подаче информации могут существенно ухудшить качество жизни сотрудников предприятия. Если в физическом смысле эксперимент можно развернуть вспять и вернуть исходные значения, то в сфере социально-экономической последствия эксперимента со СМИ вернуть в исходную позицию уже не получится [8].

Рассмотрим два способа, которые могут обеспечить большую финансовую надёжность в принятии решений:

1) Надёжность контрагентов

Тщательная проверка данных о контрагентах, с которыми предстоит заключение договора путём выполнения последовательности действий:

- запрос у контрагента всех необходимых документов для заключения сделки;

- поиск контрагента в БД ФНС;

- поиск контрагента в «чёрных списках» и негативных отзывов в сети Интернет;

- рассмотрение картотеки арбитражных дел;

- попасть в БД исполнительных производств;

- изучение единого федерального реестра в плане фактов деятельности юридических лиц;

- изучение реестров лицензий;

- проверка действительности паспорта и предлагающихся к нему данных;

- изучение государственных контрактов;

- изучение единого реестра проверок;
- изучение сайта контрагента;

- тщательный интернет-поиск данных, связанных с компанией, директором, сотрудниками;

- поиск новостей, рекламы в СМИ, связанных с компанией (обращается внимание на даты, частоту размещения информации, название СМИ, рейтинговость СМИ).

Все полученные данные анализируются с целью изучения контрагента предварительно разбиваясь на три главные категории:

- потенциал контрагента;

- финансовое состояние;

- арбитражные дела.

Главной целью анализа информации является оценка рисков при заключении договора с контрагентом. Важно понять тенденцию к росту или наоборот к убыткам контрагентам, выявить факторы, способствующие введению в заблуждение. Зачастую факторы, которые ведут в заблуждение - это информация, которая проплачена СМИ самим контрагентом. Она может сильно резонировать с реальностью. Проблема восприятия СМИ обществом заключается в том, что подавляющее большинство зрителей, читателей и слушателей воспринимают получаемую информацию с доверием без попыток проверить и поставить под сомнение подаваемую информацию. Проще всего воспринимать как истину, чем провести своё самостоятельное мини-расследование в плане целесообразности доверия к тому, или иному источнику информации.

Потенциал контрагента также можно определить опираясь на оценку его сайта, для данной процедуры необходимы квалифицированные IT-специалисты, которые имеют опыт в данной сфере. Необходимо взвешенно оценить связи контрагента, используя ту же теорию графов или подобные теории из сферы системного анализа. Как правило, именно использование теории графов ведёт к выявлению степени по рангам, весам связей с определенной организацией что делает анализ более объективным [9].

В случае если у контрагента прослеживаются долговременные судебные тяжбы, убыточность, не вызывающие доверия сделки, сомнительные связи, информация, подаваемая СМИ не соответствует реальности и намеренно искажена, то заключение договора с таким контрагентом крайне не рекомендуется во избежание проблем в ходе предполагаемого сотрудничества.

2) Экспертиза договоров и юридическое 
сопровождение

Экспертиза договора представляет собой довольно эффективный инструмент для защиты своего предприятия от спорных ситуаций в дальнейшей работе.

Задачи экспертизы договора сводятся к следующим пунктам:

- правоспособность контрагента;

- соответствие необходимых реквизитов;

- финансовая оценка;

- полномочия подписантов договора;

- статус договора с юридической стороны;

- проверка условий договора;

- проверка соответствия интересов сторон в договоре;

- проверка дат договора;

- проверка срока действия договора;

- проверка рамок ответственности в договоре;

- проверка условий отступления от договоpa;

- проверка конфиденциальности договора;

- проверка условий расторжения договора;

- проверка способов рассмотрения спорных ситуаций;

- проверка дополнительных условий;

- проверка случаев на предмет форс-мажоpa.

Экспертиза и юридическое сопровождение договора также нуждаются в тщательном си- стемном анализе с помощью информационных интернет-источников [10].

Кроме рассматриваемых выше способов необходимо разработать комплексный подход включающий вероятностное влияние СМИ, который будет состоять из следующих пунктов:

- разработка грамотной политики эффективного управления капиталом;

- разработка качественного уровня финансового менеджмента в управлении структурой предприятия;

- разработка высокооснащенной информационно-технологической базы и регулярное обновление этой базы;

- поиск квалифицированных сотрудников для высокого уровня аудирования;

- разработка системы выявления и последующей проработки экономических рисков;

- разработка перечня мер, который смог способствовать высокому уровню адаптации к стремительно меняющейся рыночной конъюнктуре.

\section{Выводы}

В заключении следует отметить высокую важность обращения внимания на вопрос влияния СМИ на финансовую безопасность как государства, так и отдельного предприятия. Недооценка рисков воздействия сторонней информации может сыграть роковую роль для финансового благополучия и прогресса в целом.

\section{Библиографический список}

1. Фундаментальный анализ рынка // Order flow trading. URL: https://orderflowtrading.ru/analitika-rynka/ fundamentalnyji-analiz/ (дата обращения: 09.11.2019).

2. Основные внутренние угрозы информационной безопасности 2019 // Anti-malware. URL: https://www.antimalware.ru/analytics/Market_Analysis/key-infosecurity-business-trends (дата обращения: 09.11.2019).

3. Володина И.Г. Пути обеспечения финансовой безопасности предприятия // Молодой ученый. 2013. № 9. C. $156-160$.

4. Шерн Р.П. Что мешает эффективно востребовать дебиторскую задолженность // Финансы предприятия 2012 г.

5. Шерн Р.П. Договор с клиентом как инструмент продаж // Продажи-2009 г.

6. Юридическая экспертиза договоров // Юрист компании 2017 г.

7. Хахонова, И.И. Развитие методики управления финансовыми рисками / И.И. Хахонова // Фундаментальные исследования. - 2012.- № 6-1.- С. 268-272.

8. Осавелюк Елена Алексеевна Роль средств массовой информации (сми) в обеспечении информационной безопасности России на евразийском пространстве // Международное сотрудничество евразийских государств: политика, экономика, право. 2016. № 3 (8). URL: https://cyberleninka.ru/article/n/rol-sredstvmassovoy-informatsii-smi-v-obespechenii-informatsionnoy-bezopasnosti-rossii-na-evraziyskom-prostranstve (дата обращения: 09.06.2019).

9. Устинова Л.В. Влияние СМИ на социальные процессы в обществе // Российская наука и образование сегодня: проблемы и перспективы. 2015. № 1 (4). С. 101-102.

10. Романов В.Ю. Влияние СМИ на экономику. Центральный научный вестник. 2017. Т. 2. № 21 (38). С. 35-36. 